\title{
Microwave-Based Diesel Particulate Filter Monitoring - Soot Load Determination and Influencing Parameters
}

\author{
M. Feulner, A. Müller, G. Hagen, D. Brüggemann, R. Moos \\ Bayreuth Engine Research Center (BERC), Zentrum für Energietechnik (ZET), \\ Universitätsstr. 30, 95440 Bayreuth, Germany, \\ Markus.Feulner@uni-bayreuth.de
}

\begin{abstract}
Diesel particulate filters (DPF) are essential for diesel exhaust gas aftertreatment in the automotive sector. For soot load determination, a novel approach using microwaves emerged recently. Based on the electrical conductivity of soot particles, the soot load of the DPF can be measured directly and in a contactless way by this method. Microwaves are impressed into the filter housing and the reflection and transmission is measured. In this study, in-operation dynamometer measurements are presented. Tests of filter loading at constant operation conditions as well as engine speed and load variations at constant soot load were conducted. The results obtained from weighed soot mass, differential pressure signals, and the microwave data agree well. Soot load determination with the microwavebased method is possible. A clear dependency of temperature needs to be corrected, whereas exhaust gas mass flow seems to have no notable influence.
\end{abstract}

Key words: diesel particulate filters (DPF), soot load determination, cavity perturbation, electrical conductivity, microwaves.

\section{Introduction}

In order to meet the tight emission standards in the field of automotive pollution control, the use of a DPF has become indispensable. For a fuel efficient engine control and filter regeneration strategy, a precise knowledge of the actual trapped soot mass inside the DPF is required. It is state of the art to determine the soot load indirectly and model-based with differential pressure measurements [1]. A novel approach is based on a microwave measurement technique that enables direct and contactless in-operation soot load detection [2-4]. This microwave-based (RF) method has already been proven as being basically suitable for detecting the soot load of a DPF. In this contribution, not only the performance of the measurement system during soot loading will be analyzed, but also influencing parameters like e.g. exhaust gas temperature will be discussed.

\section{Fundamentals}

Microwaves are impressed into the filter housing by a vector network analyzer (VNA) via coaxial antennas, and the scattering parameters $S_{22}$ (reflection) and $S_{12}$ (transmission), which are a function of frequency, are measured. Thereby, the canning serves as a cavity resonator, in which the electro-magnetic waves form resonance modes at characteristic frequencies [2]. These resonance frequencies, $f_{\text {res, }}$ and other parameters like attenuation or transmission losses can be derived from the measured ISIspectra $[2,5]$. The spectra are a function of the dielectric properties of the material inside the resonator as well as of its size and geometry. With increasing soot inside the filter, the overall dielectric properties inside the resonator change due to the good conductivity of soot compared to that of the ceramic filter material [6]. Therefore, from observing different parameters of the ISI-spectra, like resonance frequency or attenuation, the actual trapped soot mass can be determined. As the electrical conductivity and resonator geometry depend on temperature, it is expected that the exhaust gas temperature influences the measurements. Increasing temperature will e.g. lead to a decreasing resonance frequency [2].

\section{Measurement Setup and Methods}

For the microwave measurements, an uncoated aluminum titanate filter ( $\varnothing 5.66 "$ ", length 6", volume $V_{\text {DPF }} \approx 2.47 \mathrm{I}$, cell density $300 \mathrm{cpsi}$ ) was installed into the exhaust pipe of a 3.0 ITDI engine in a dynamometer test bench (fig. 1). Two RF-antennas were mounted into the canning, up- and downstream of the filter 
monolith, and connected to the VNA (Anritsu MS 2028B) to impress the microwaves in a frequency range from $500-2500 \mathrm{MHz}$ into the housing. To define the resonator length exactly, a wire mesh was mounted at both ends of the canning.
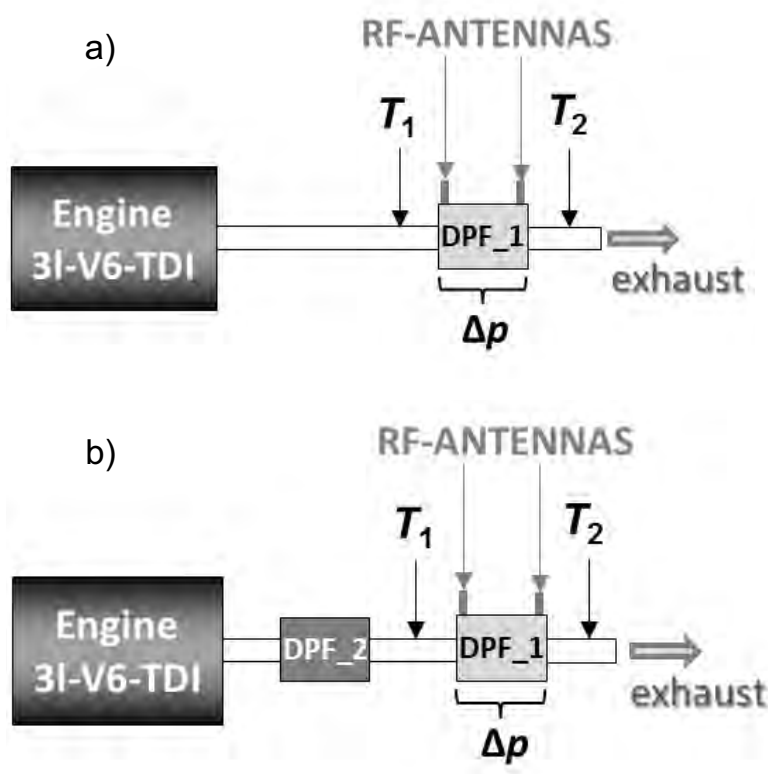

Fig. 1: Setup for the test bench measurements; a) soot loading experiment, b) measurement with constant soot mass inside the DPF.

Two types of experiments were conducted:

Type 1 - Fig. 1a: In various test cycles, the DPF was loaded with different amounts of soot $\left(2.0,4.6,10.9 \mathrm{~g}_{\mathrm{soot}} / \mathrm{I}_{\mathrm{DPF}}\right)$ at constant engine parameters (2350 rpm, $20 \%$ load). For comparison with the microwave-based system the actual trapped soot mass was determined gravimetrically from time to time and the differential pressure, $\Delta p$, was measured continuously over the filter.

Type 2 - Fig. 1b: In order to analyze influencing parameters on the measurement system, another filter in a separate housing (DPF_2) was installed upstream of DPF_1, so that the soot mass inside the observed DPF 1 was kept constant during engine operation. So, different engine operation points were set and the microwave parameters were measured. The measuring program included seven engine settings (variation between 1000-2350 rpm; 0$100 \%$ load) and was conducted six times: once with an empty canning at the position of DPF_1, twice with a soot-free DPF, and once with $2.2 \mathrm{~g} / \mathrm{l}_{\mathrm{DPF}}, 4.6 \mathrm{~g} / \mathrm{I}_{\mathrm{DPF}}$ and $10.9 \mathrm{~g} / \mathrm{I}_{\mathrm{DPF}}$ soot trapped inside the filter. For the interpretation of the measurements concerning influencing parameters, the measured inlet exhaust gas temperature, $T_{1}$, and a calculated exhaust gas mass flow, $m_{\text {Exhaust }}$, are taken into account.

\section{Results and Discussion}

Fig. 2 shows the frequency shift of one resonance peak during soot loading (experiment type 1). For sake of clarity, $f_{\text {res }}$ is plotted reversely. Additionally, the measured differential pressure and gravimetrically determined soot mass in the filter are shown. The pause in the curves of $f_{\text {res }}$ and $\Delta p$ indicates when the engine was stopped and the DPF in its housing was dismounted for weighing.

The resonance frequency moves towards lower values linearly with increasing soot mass, as expected from [2]. The very good agreement between $f_{\text {res }}$ and $\Delta p$ becomes obvious.

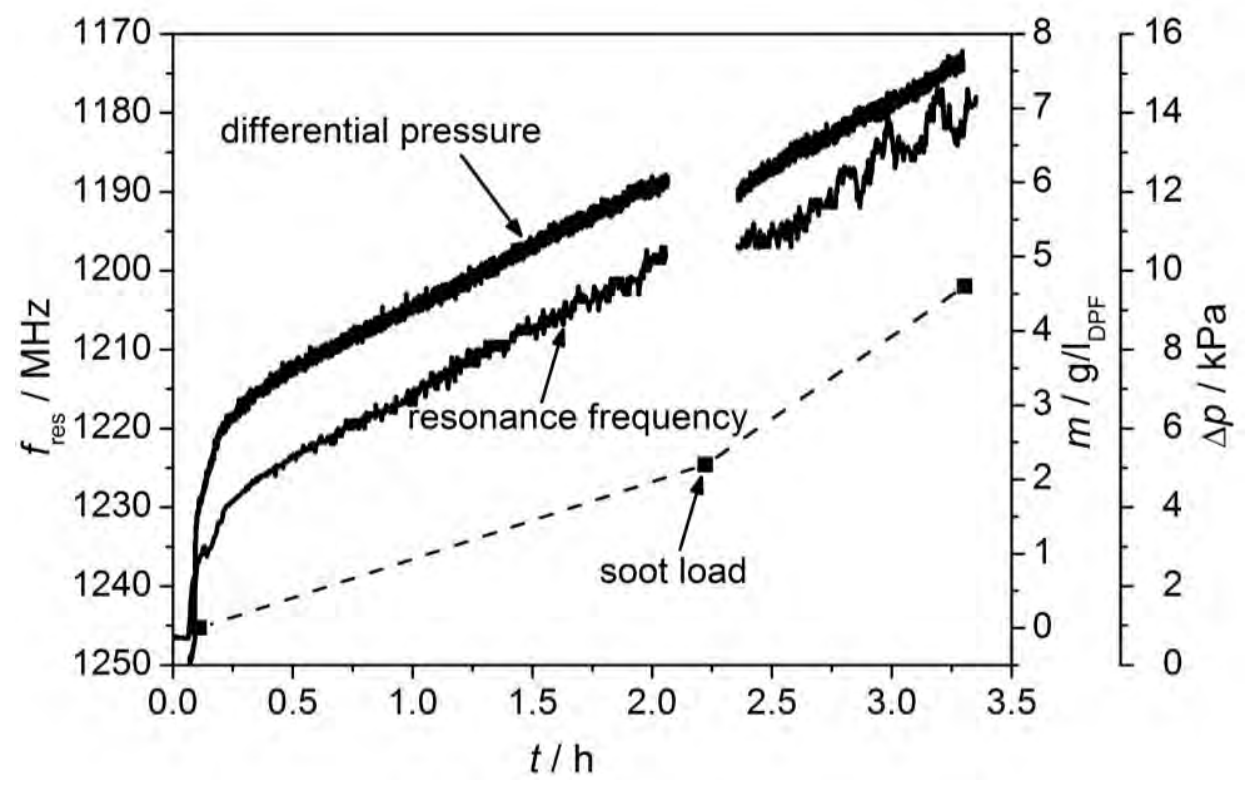

Fig. 2: Resonance frequency (reversely plotted), differential pressure and weighed soot mass during filter loading at constant speed and load (2350 rpm, $\left.20 \%, T_{\text {Exh. }} \approx 230{ }^{\circ} \mathrm{C}\right)$ 
Results of the test with constant soot load and varying engine parameters (experiment type 2) are shown in fig. 3 exemplarily during the cycle with a soot-free DPF. Fig. 3 shows the resonance frequency (reversely plotted) of the resonance mode around $1200 \mathrm{MHz}$, the exhaust gas temperature and mass flow.

During the test, $f_{\text {res }}$ follows inversely the exhaust gas temperature; higher temperatures lead to a lower frequency. This strong dependency was expected and can be attributed to a conductivity increase of the dielectric and to the thermal expansion of the canning.

The behavior of mass flow differs from that of temperature and also from $f_{\text {res. }}$. Unfortunately, exhaust gas temperature and mass flow are not independent. Variation of the engine parameters lead to a change of both values. It seems that there is no significant influence of mass flow, but of temperature. This behavior is confirmed by another group [7] that worked with a commercial soot sensor [8].

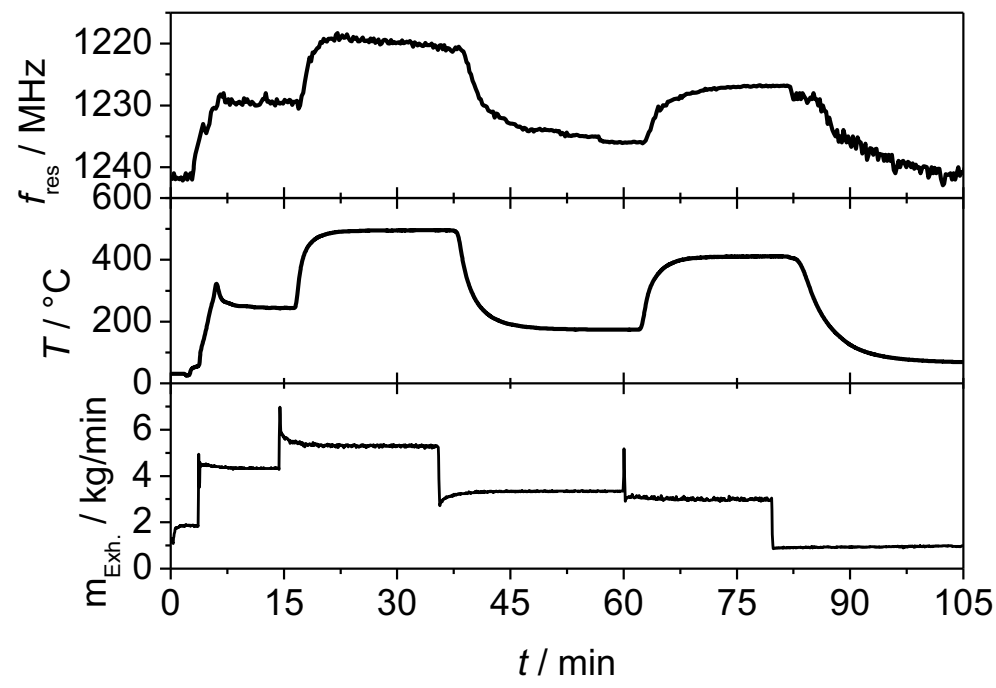

Fig. 3: Resonance frequency, exhaust gas temperature and mass flow during engine parameter variation with a soot-free DPF.

The above described data (fig. 2 and 3) are derived from the $S_{22}$-parameter. The resonance frequency can be determined continuously from the measured spectrum of the reflection parameter $S_{22}$.

The simultaneously taken transmission signals can also be evaluated. The spectra of $\left|S_{12}\right|$ are averaged over frequency in a range from 945 $2500 \mathrm{MHz}$. This calculated average values can be taken as a measurand. In fig. 4, the results of all test cycles (empty canning, soot-free DPF and DPF with three different soot loads) of the second experiment (constant soot mass) are plotted against exhaust gas temperature.

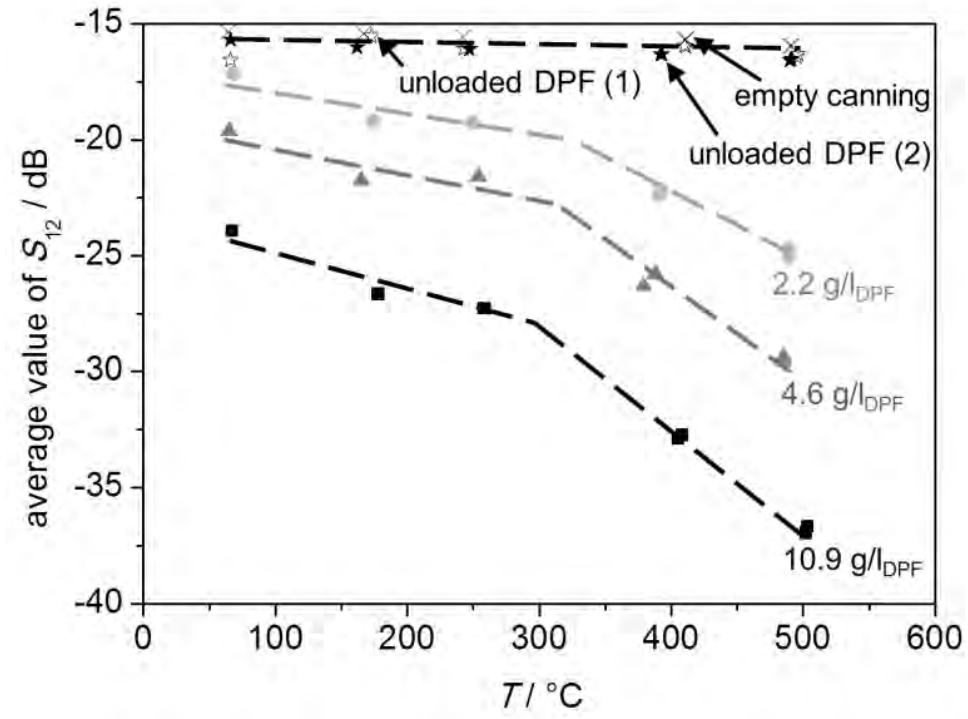

Fig. 4: Average value of the $I S_{12} I$-parameter over exhaust gas temperature during test cycles with constant soot load. 
One can clearly see that the values of the canning without filter and with a soot-free filter are nearly equal and independent from temperature. The influence of canning expansion is consequently negligible. Also the DPF-monolith itself seems to have no great influence to the average value of the $S_{12}$-signal. This can be expected, since without conductive soot loading, almost no losses occur. With increasing soot mass, the averaged $S_{12}$ at a given temperature declines. Furthermore it becomes more and more sensitive to a change of temperature. Obviously, the influence of the material properties of soot, like electrical conductivity, becomes increasingly important with accumulating soot mass inside the filter and leads to this temperature dependent behavior. Operation points resulting in equal temperatures lead to similar $S_{12}$-values (e.g. at $\left.400{ }^{\circ} \mathrm{C}\right)$.

\section{Conclusion and Outlook}

A clear temperature dependency can be seen in the reflection as well as in the transmission parameters. This needs to be corrected for soot load estimation with the RF-method. Generally, the system is suitable for determining the soot load of a DPF. Additionally to the resonance frequency derived from the $\left|S_{22}\right|$-spectrum, the transmission measurement and averaging seems to be a promising possibility for a later application.

In further work, other parameters, like humidity of the soot have to be examined. Also the potential of the microwave-based method for a locally resolved soot load detection and OnBoard Diagnosis of the DPF will be evaluated in future.

\section{Acknowledgement}

The author R.M. is indebted to the German Research Foundation (DFG) for financial support under grant number MO 1060/6-2.

\section{References}

[1] D. Rose, T. Boger, Different Approaches to Soot Estimation as Key Requirement for DPF Applications, SAE paper 2009-01-1262 (2009); doi: 10.4271/2009-01-1262

[2] G. Fischerauer, M. Förster, R. Moos, Sensing the soot load in automotive diesel particulate filters by microwave methods, Meas. Sci. Tech. 21, 035108 (2010); doi: 10.1088/09570233/21/3/035108

[3] M. Feulner, G. Hagen, A. Müller, D. Brüggemann, R. Moos, In-Operation Monitoring of the Soot Load of Diesel Particulate Filters with a Microwave Method, IMCS 2012 - The 14th International Meeting on Chemical Sensors,
1422-1425 (2012); doi:

10.5162/IMCS2012/P2.2.6

[4] A. Sappok, L. Bromberg, J. Parks, V. Prikhodko, Loading and Regeneration Analysis of a Diesel Particulate Filter with a Radio Frequency-Based Sensor, SAE paper 2010-01-2126 (2010), doi: 10.4271/2010-01-2126

[5] G. Fischerauer, M. Spörl, A. Gollwitzer, M. Wedemann, R. Moos, Catalyst State Observation via the Perturbation of a Microwave Cavity Resonator, Frequenz 62, 180-184 (2008); doi: 10.1515/FREQ.2008.62.7-8.180

[6] T. Birkhofer, A. Knezevic, R. Müller, C. Plog, Method of operating a diesel particle filter, European patent application, EP 1564387 A1, (2005)

[7] J. Hansson, V. Ingeström, A Method for Estimating Soot Load in a DPF Using an RFbased Sensor, Master Thesis, University of Linköping (2012), ISRN: LiTH-ISY-EX--12/4584SE

[8] General Electrics, Accusolve Diesel Particulate Filter (DPF) Soot Sensor (2011), http://www.gemcs.com/download/temperature/Accusolve_Soot _Sensor. 